\title{
Stent-Assisted Coiling Treatment of Pediatric Traumatic Pseudoaneurysm Resulting from Tumor Surgery
}

\author{
Christopher S. Ogilvy ${ }^{a-d}$ Rabih G. Tawk ${ }^{b, c, e} \quad$ Maxim Mokin $^{f} \quad$ Xinyu Yang ${ }^{a, g}$ \\ Elad I. Levy ${ }^{b, c, e}$ L. Nelson Hopkins ${ }^{b, c, e}$ Adnan H. Siddiqui ${ }^{b, c, e}$ \\ ${ }^{a}$ Neurovascular Service, Massachusetts General Hospital, Boston, Mass., b Department of Neurosurgery and \\ Toshiba Stroke Research Center, ' ${ }^{\circ}$ Department of Radiology, School of Medicine and Biomedical Sciences, \\ University at Buffalo, State University of New York, ${ }^{\mathrm{d}}$ Department of Neurosurgery, Kaleida Health, ${ }^{\mathrm{e}}$ Department \\ of Neurosurgery, Kaleida Health, and f Department of Neurology, School of Medicine and Biomedical Sciences, \\ University at Buffalo, State University of New York and Kaleida Health, Buffalo, N.Y., USA; ${ }^{9}$ Department of \\ Neurosurgery, Tianjin Medical University General Hospital, Tianjin, China
}

\section{Key Words}

Endovascular coiling • Stent placement · Traumatic pseudoaneurysm

\begin{abstract}
Background: Traumatic intracranial pseudoaneurysms in children are typically the result of blunt or penetrating head injury. There are isolated reports of pseudoaneurysm as the result of intracranial aneurysm surgery in both adults and children. Treatment of these lesions, both surgically and endovascularly, can be complicated due to the known variability of arterial wall thickness in traumatic pseudoaneurysms. Case Report: We describe a child who underwent successful craniopharyngioma resection following staged surgical procedures. Follow-up imaging 8 months after the operation demonstrated an enlarging pseudoaneurysm of the left supraclinoid carotid artery. The lesion was successfully treated with stenting of the vessel and coil placement between the stent and the aneurysmal segment of the artery. Follow-up angiographic imaging 6 months later revealed complete
\end{abstract}

obliteration of the aneurysm and normalization of the carotid artery lumen. Conclusion: To our knowledge, this is the first report of a pseudoaneurysm secondary to a surgical intervention in childhood that was treated with stent-assisted coiling. This strategy of vascular reconstruction is increasingly used in adults and appears safe to implement in the pediatric population. However, the long-term outcomes and the value of using an antiplatelet regimen in this young population are still to be determined.

Copyright $\odot 2012$ S. Karger AG, Basel

Traumatic intracranial pseudoaneurysm is a known potential complication of head injury. Because of the rarity of congenital intracranial aneurysms in childhood, the pediatric population has a disproportionate representation of traumatic pseudoaneurysms, accounting for up to one third of all aneurysms encountered in children [1-3]. Although the majority of these aneurysms occur as a result of blunt or penetrating trauma, there are reports of pseudoaneurysms that have resulted from intracranial

\section{KARGER}

Fax +41613061234 E-Mail karger@karger.ch www.karger.com

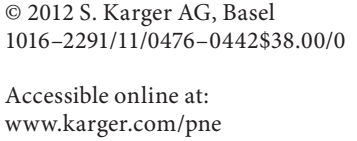

Adnan H. Siddiqui, MD, PhD

University at Buffalo Neurosurgery

100 High Street, Suite B4

Buffalo, NY 14203 (USA)

Tel. +1 716218 1000, ext.5133, E-Mail asiddiqui@ubns.com 


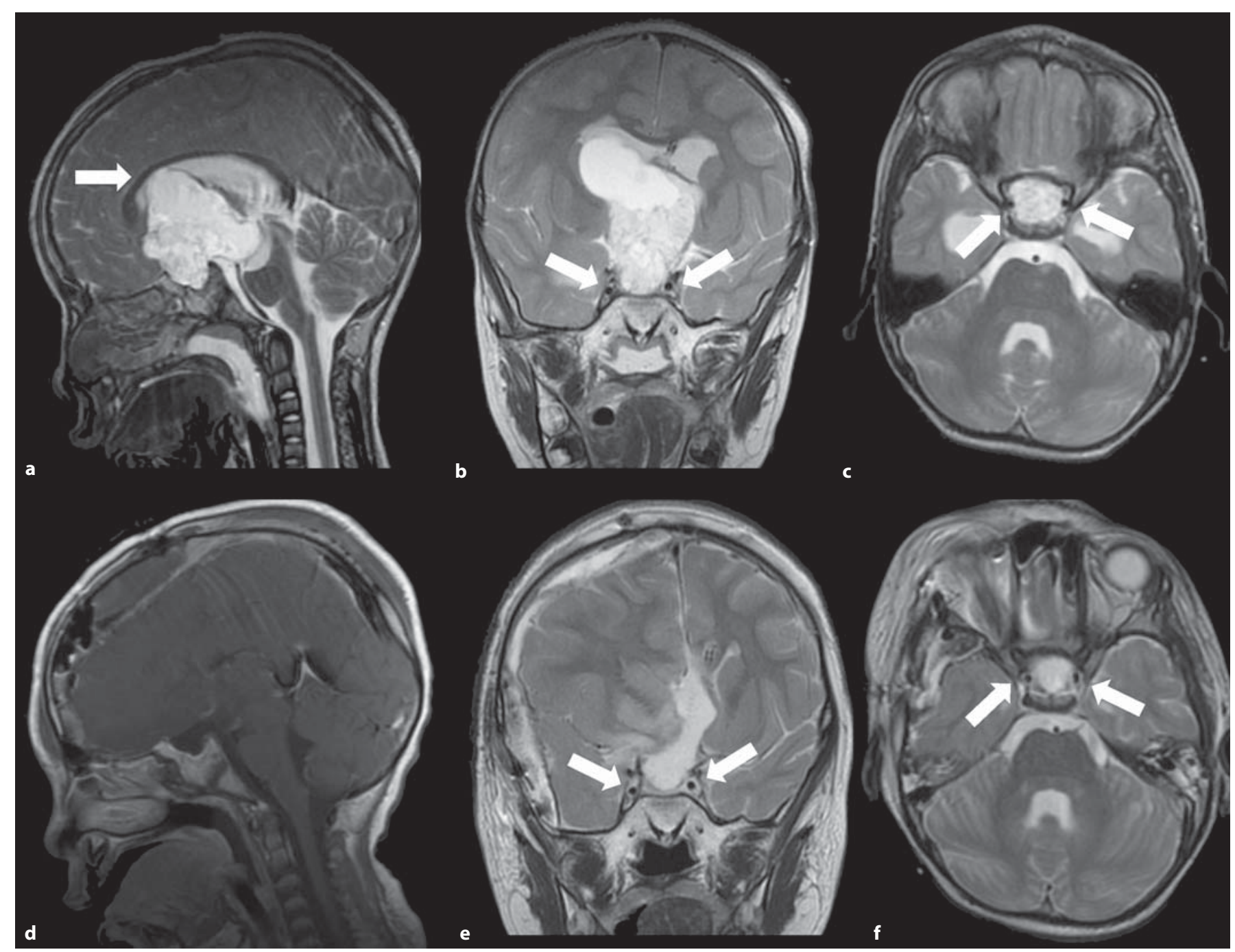

Fig. 1. $\mathrm{T}_{2}$-weighted axial MR images (a, sagittal; $\mathbf{b}$, coronal; $\mathbf{c}$, axial) at the time of initial presentation of the patient described. The carotid arteries appear normal in caliber and adhere to the tumor (b, c; arrows). The tumor extends well into the third ventricle on sagittal (a; arrow) imaging. Sagittal $\mathrm{T}_{1}(\mathbf{d})$, coronal $\mathrm{T}_{2}(\mathbf{e})$, and axial $\mathrm{T}_{2}$ (f) images show an immediate postoperative view with gross total resection of the lesion. The carotid arteries appear normal in diameter (e, $\mathbf{f}$; arrows).

surgery in both pediatric and adult patients [4-7]. Whether iatrogenic or traumatic, treatment of pseudoaneurysms can often prove difficult because the entire vessel can be involved with the lesion, resulting in a fusiform dilatation of the vessel; therefore, treatment may involve vessel occlusion, vessel segment replacement, vessel reconstruction with clipping, or occlusion with an extracranial-to-intracranial bypass procedure [8-10]. Sutton [11] reported an update on a series of 11 patients who underwent surgery for craniopharyngiomas and chiasmatic gliomas that developed fusiform dilatation of the carotid artery. One patient developed headaches and likely hemorrhage and had a poor outcome from microsurgical treatment of this lesion. Therefore, it was recommended that surgical exploration be reserved for symptomatic patients and observation for asymptomatic patients. As endovascular techniques have evolved, treatment of pseudoaneurysms has been reported with endovascular reconstruction utilizing intravascular stents, direct coiling, or a combination of stents and coils, or liquid embolic agents $[5,12-20]$. 

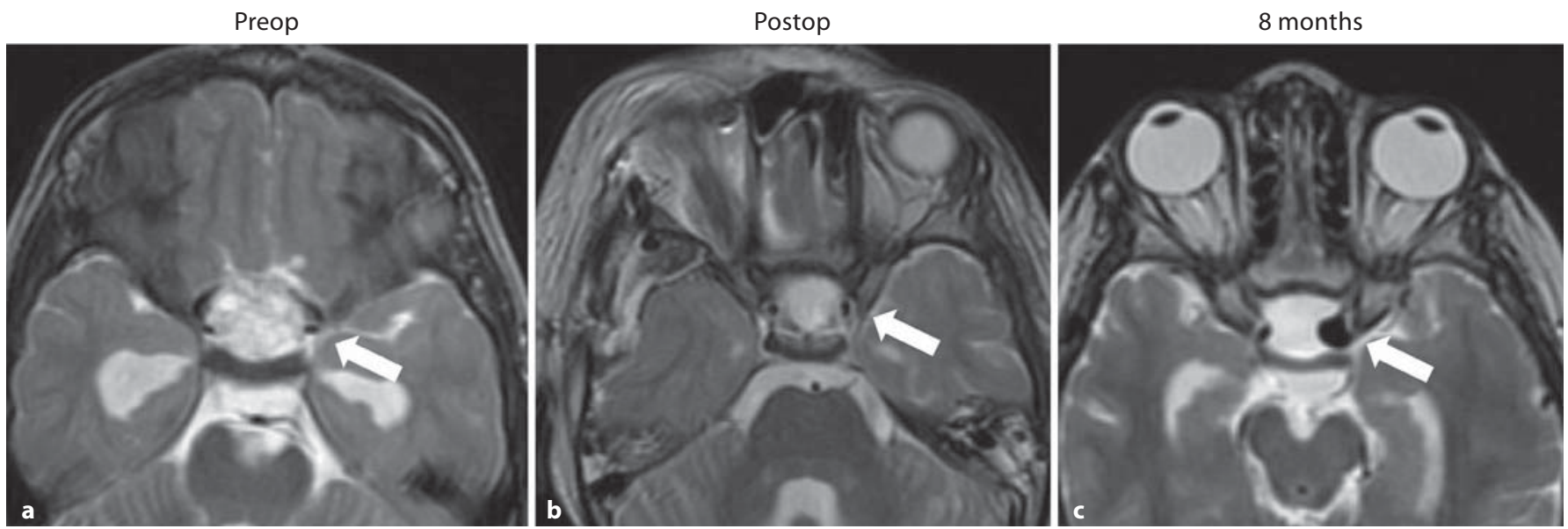

Fig. 2. $T_{2}$ axial imaging demonstrates immediate preoperative (a) and postoperative (b) views with gross total resection of the lesion. The left carotid artery appears normal in diameter (arrows). $\mathrm{T}_{2}$-weighted axial imaging obtained 8 months after surgery shows enlargement of the left carotid artery (c; arrow).

In this report, we describe a 5-year-old boy who underwent successful resection of a craniopharyngioma. Initial postoperative imaging revealed no vascular abnormalities. Subsequently, an asymmetric aneurysmal enlargement of the left supraclinoid carotid artery was noted to grow progressively to $4 \mathrm{~mm}$ at 3 months and then to $8 \mathrm{~mm}$ at 8 months. Although the child remained asymptomatic, the rapid, asymmetric enlargement of the lesion was concerning, and he was successfully treated with stenting of the vessel and coil placement between the stent and the aneurysmal segment of artery. Follow-up imaging 6 months after treatment revealed complete obliteration of the aneurysm and normalization of the carotid artery lumen.

\section{Case Report}

\section{History and Examination}

This patient initially presented at the age of 4 years with a 1-week history of persistent headache. At the time of admission, he was noted to have right facial weakness and right pronator drift. A cranial computed tomographic (CT) scan demonstrated a large, cystic suprasellar mass extending through the third ventricle into the right frontal horn with a mild amount of calcification in the periphery. Magnetic resonance (MR) imaging and MR angiography studies demonstrated a large suprasellar tumor with heterogeneous enhancement, consistent with a diagnosis of craniopharyngioma (fig. 1a-c, 2a). Obstructive hydrocephalus with enlarged lateral ventricles and transependymal flow of cerebrospinal fluid was also noted. A ventriculostomy was placed, and the patient subsequently underwent a right parasagittal cra- niotomy with a transcallosal approach to the craniopharyngioma using frameless stereotactic navigation. A subtotal resection of the tumor was accomplished, leaving the tumor margins adjacent to the carotid artery and hypothalamic structures for a second surgery. The patient awoke from surgery with no new neurologic deficits. During the second-stage surgery 6 days later, a right pterional and orbitozygomatic craniotomy was performed that resulted in gross total resection of the tumor. Postoperative MR imaging and MR angiography demonstrated complete resection of the tumor and an apparent normal caliber of the carotid arteries bilaterally (fig. 1d-f, 2b). Follow-up MR imaging and MR angiography 3 months after surgery revealed a 4 -mm fusiform enlargement of the left paraclinoid internal carotid artery. As suggested by Sutton [11], a decision was made to follow up conservatively given the absence of symptoms. Six months thereafter, 8 months after the initial surgery (when the patient was 5 years old), MR angiography demonstrated asymmetric enlargement of the aneurysm to $8 \mathrm{~mm}$ (fig. 2c). The patient remained intact from a neurologic standpoint after his initial surgery with resolution of his headaches. Given the asymmetric, progressive, and rapidly enlarging nature of the lesion, it was decided to proceed with angiography and balloon test occlusion followed by treatment of the diseased segment of the artery with stent-assisted coiling.

\section{Intervention}

Under general anesthesia, the patient was monitored with somatosensory evoked potential monitoring as well as electroencephalography (EEG). A cerebral angiogram demonstrated the left carotid pseudoaneurysm (fig. 3a, b) as well as an atretic right A1 segment that did not fill on angiography, even during temporary digital occlusion of the left carotid artery. A test occlusion of the left carotid artery was performed by placing a 5 -french Envoy NPD catheter (Cordis, Warren, N.J., USA) in the prepetrous segment of the carotid artery and advancing a $4 \times 7 \mathrm{~mm}$ Hyperform balloon (MicroTherapeutics, Irvine, Calif., USA) into the petrous 
Fig. 3. Angiography confirmed the pseudoaneurysm in the supraclinoid segment of the carotid artery on the left side (a, oblique AP view; b, lateral view; arrows). Following stent deployment, two separate coils were placed in the aneurysmal sac between the stent and aneurysmal wall (c-e; arrows).

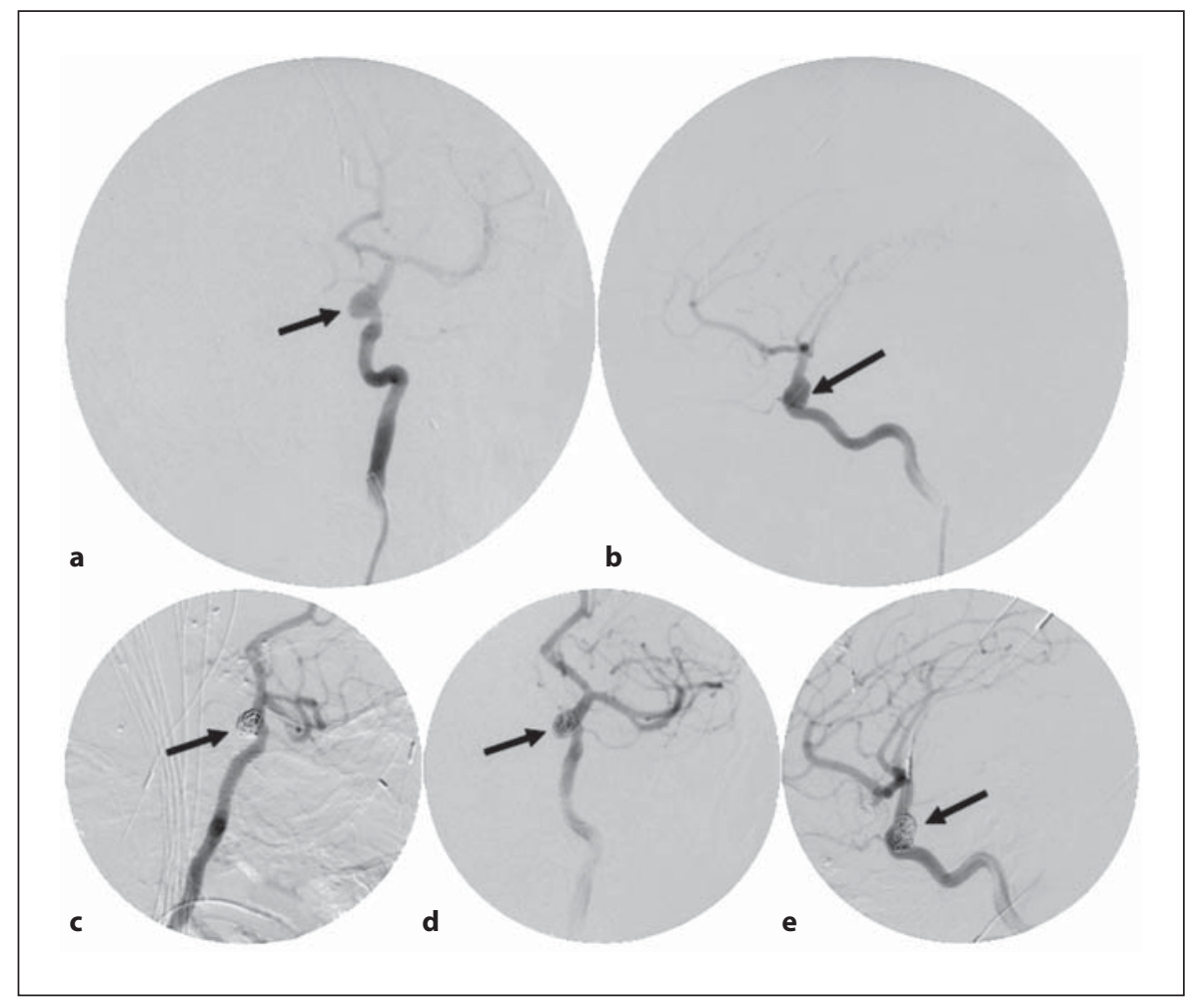

segment of the carotid artery. Test occlusion for $30 \mathrm{~min}$ with mean blood pressure lowered to $50 \mathrm{~mm} \mathrm{Hg}$ demonstrated no change in the EEG recording or the somatosensory evoked responses. Given the atretic Al segment, we felt that a vessel-sparing procedure should be undertaken if possible.

We deployed a $4.5 \times 22 \mathrm{~mm}$ Enterprise stent (Codman and Shurtleff, Raynham, Mass., USA) in the carotid artery from a level just below the carotid bifurcation to a segment of the carotid artery proximally at the level of the distal cavernous internal carotid artery. With the stent deployed, we proceeded to coil the pseudoaneurysm by advancing an LPES 45-degree angle microcatheter (Codman and Shurtleff, Inc.) between the tines of the stent into the pseudoaneurysm. Two separate coils were deployed: a $5 \mathrm{~mm} \times 12 \mathrm{~cm}$ Cashmere Complex 14 Cerecyte coil (Micrus Endovascular, San Jose, Calif., USA) and a $3 \mathrm{~mm} \times 8 \mathrm{~cm}$ Hypersoft Microplex 10 helical coil (MicroVention Inc., Aliso Viejo, Calif., USA). With this construct in position, we had what appeared to be excellent filling of the left carotid artery with obliteration of the asymmetric dome and only minimal residual stasis within the pseudoaneurysm (fig. $3 \mathrm{c}-\mathrm{e}$ ). The patient tolerated the procedure well and had no new neurologic deficit following emergence from anesthesia. He was placed on clopidogrel ( $75 \mathrm{mg}$ by mouth on a daily basis) and aspirin (5 mg/kg by mouth on a daily basis) 1 week prior to treatment and was maintained on this regimen after the procedure for a total of 3 months. A gadolinium-enhanced MR angiogram obtained at 3 months revealed no filling of the aneurysm and good flow proximal and distal to the stent. Clopidogrel was discontinued, although aspirin was continued. An angiogram at 6 months revealed complete obliteration of the aneurysm and restoration of normal luminal patency of the left carotid artery (fig. $4 \mathrm{a}, \mathrm{b}$ ). The child remained completely asymptomatic after treatment and throughout the follow-up period (now 1 year). To evaluate the patency of the stent and ensure complete aneurysm obliteration, we plan to obtain follow-up gadolinium-enhanced MR angiograms in the future.

\section{Discussion}

Traumatic pseudoaneurysms are typically the result of penetrating or blunt head injury. In this context, the term pseudoaneurysm is often hard to define as the dilatation seen in the artery may represent a partial thickness tear in the artery wall with thinning of the wall and protrusion of the remaining layers of arterial wall anatomy. There are situations in which the pseudoaneurysm represents a hematoma surrounding a vessel tear. In this situation, there is no true arterial wall around the area of enlargement seen on a conventional arteriogram or a CT angiogram. Instead, blood is flowing out of the artery and through a hematoma cavity and then back into the distal artery. In the patient we describe, the mechanism of pseudoaneurysm formation is much more likely that of a partial arterial injury with resultant thinning of the wall and 
Fig. 4. Six-month follow-up angiographic images showing the coil mass and the stent with a patent lumen. The aneurysmal sac is obliterated, and there is no evidence of in-stent thrombosis (a, oblique AP view; b, lateral view).
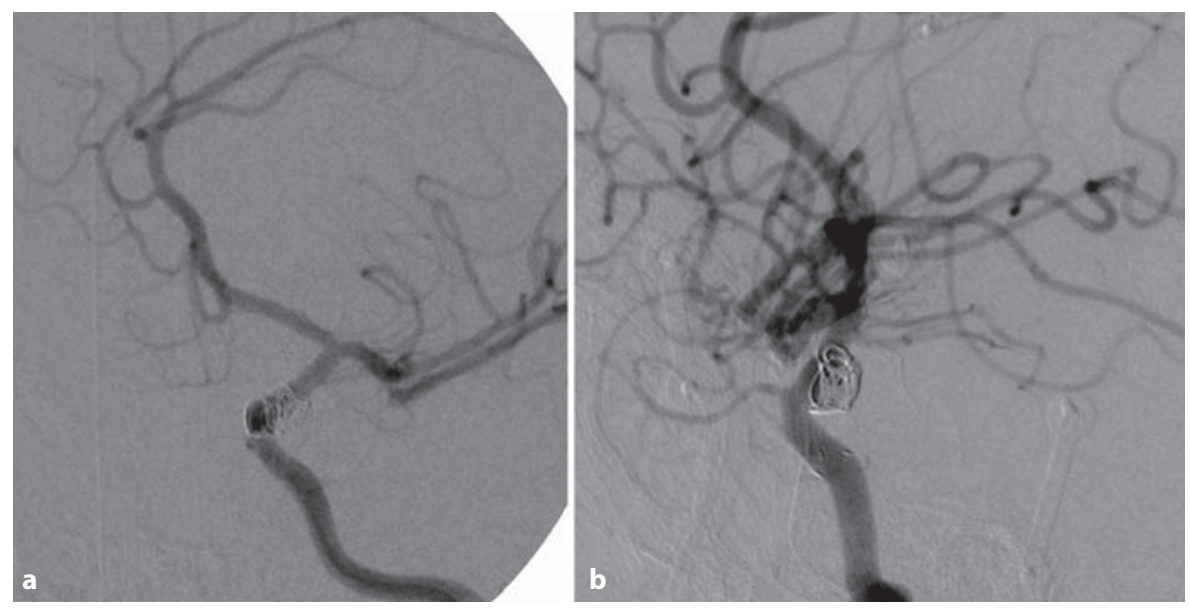

subsequent bulging to form the asymmetric pseudoaneurysm we observed.

Pseudoaneurysms are a known complication of intracranial tumor surgery. Dunn et al. [4] report a traumatic pericallosal artery as a result of transcallosal resection of a hypothalamic pilocytic astrocytoma. Traumatic pseudoaneurysms have also been described following transsphenoidal surgery and spine surgery, causing carotid artery injury and vertebral artery injury, respectively [5]. Interestingly, fusiform dilatations have been described in the carotid artery following surgery for childhood craniopharyngiomas $[6,21]$. In the description by Sutton et al. [6], 9 of 31 (29\%) patients were found to have fusiform dilatation of the supraclinoid carotid artery either at the time of surgery for tumor recurrence ( 1 patient) or on follow-up CT imaging performed 6-18 months after surgery (8 patients). Those authors did not treat any of the observed dilatations and reported no incidence of hemorrhage at a mean followup of 3.7 years after diagnosis. Sutton [11] also reported on 11 children who developed fusiform dilatation of the carotid artery following resection of craniopharyngiomas and hypothalamic tumors. Only one child in this group suffered a subsequent hemorrhage during a follow-up period of 5-11 years. According to Levy et al. [22], aneurysms of traumatic origin exhibit a greater propensity for intraoperative rupture than congenital lesions because of the presence of dense arachnoid adhesions. Because these aneurysms are mostly pseudoaneurysms, clipping of the aneurysm without sacrifice of the parent artery may not be possible [23]. Therefore, surgical treatment is associated with significant morbidity and a reported mortality of $18-29 \%$ [24].
Overall, the natural history of this cohort of iatrogenic lesions appears poorly defined, and the course of action in the face of progressive enlargement of an asymmetric aneurysmal lesion remains unclear, especially in the pediatric population. In adults, such progressive enlargement (from $0 \mathrm{~mm}$ after surgery to $4 \mathrm{~mm}$ at 3 months and then $8 \mathrm{~mm}$ at 8 months) would be considered a harbinger of a particularly aggressive and high-rupture-risk lesion. In the patient we report, it was precisely this rate of asymmetric grow th that resulted in a change in course from radiographic follow-up to consideration of intervention. An increasing number of reports describe the use of endovascular techniques to treat traumatic pseudoaneurysms [5, 12, 13, 15-19]. In most of these reports, the lesions treated are either spontaneous dissections with pseudoaneurysm or traumatic lesions caused by penetrating or blunt head injury. In the report by Lempert et al. [5], there were three pseudoaneurysms caused by transsphenoidal surgery and one that was observed in the vertebral artery after a cervical diskectomy. To date, three strategies were described for the use of endovascular techniques to treat traumatic pseudoaneurysms. The lesion can be treated with coils alone if it is a more saccular pseudoaneurysm. This approach carries a higher potential risk of rupture, because a pseudoaneurysm has a wall that is unpredictable in its ability to contain the coil mass $[5,12]$. Alternatively, techniques utilizing stent-supported coil embolization have been described to treat fusiform and wide-necked pseudoaneurysms [18]. Finally, stent therapy alone was described by Fiorella et al. [13] in the treatment of 10 patients with 'uncoilable' intracranial pseudoaneurysms. The patient we describe tolerated 
balloon test occlusion of the internal carotid artery with the mean blood pressure lowered on the basis of somatosensory evoked potential monitoring as well as EEG recording. He had an atretic A1 segment on the right side that was not well visualized on angiography. Given this feature and because the patient was 5 years of age, we felt that a vessel-sparing maneuver should be primarily attempted. Consideration was given to the possibility of extracranial-to-intracranial bypass with vessel occlusion proximal to the diseased segment of artery. We felt that the risk of another intracranial surgery could be avoided if an endovascular strategy could be utilized safely. We therefore decided to proceed with a strategy of stent deployment and coil deposition between the stent and the wall of the diseased vessel. Although this strategy required prolonged dual antiplatelet therapy (3 months), we felt this was superior to the possibility of vessel sacrifice, given the patient's young age. In a pediatric population, aspirin should be used with extreme caution given its known - albeit rare (fortunately) - association with Reye's syndrome, which can be lifethreatening [25]. Therefore, when surgical treatment options are explained to the patient and family, any long-term medication regimens that are required should also be discussed in detail, including the potential associated risks.

This is, to our knowledge, the first report of stent-assisted coil embolization of a likely postsurgical iatrogenic carotid artery pseudoaneurysm. This treatment was successful, with follow-up imaging demonstrating complete obliteration of the pseudoaneurysm and normalization of the carotid artery lumen. It should be re-emphasized that the vast majority of these postoperative lesions have a benign natural history and require only radiographic surveillance. However, for the very small subset that continues to asymmetrically enlarge, treatment options remain complex. Stent-assisted coiling may allow for vessel preservation and avoidance of a reoperation for an extracranial-intracranial high-flow bypass, which in the pediatric population is not considered a low-risk endeavor [26].

The case described in this report highlights the importance of follow-up imaging not only with MR imaging but also with MR angiography studies after significant intracranial surgery. Specifically, attention should be paid to the intracranial vasculature for any lesion that is dissected free from large intracranial vessels. In the small cohort of pediatric patients that needs to have consideration for aneurysm treatment, stent-assisted coil embolization may be a viable option.

Postsurgical Stent-Assisted Coiling of Pediatric Traumatic Pseudoaneurysm

\section{Acknowledgements}

We thank Paul H. Dressel, BFA, for preparation of the illustrations and Joyce Davis and Debi Zimmer for editorial assistance.

\section{Disclosure Statement}

Drs. Mokin, Tawk, and Yang report no financial relationships. Dr. Hopkins receives grant/research support from St. Jude Medical and Toshiba; serves as a consultant to Abbott, Boston Scientific ${ }^{1}$, Cordis, Micrus, and W.L. Gore; holds a financial interest in AccessClosure, Augmenix, Boston Scientific ${ }^{1}$, Claret Medical Inc., Micrus, and Valor Medical; has a board/trustee/officer position with AccessClosure and Claret Medical Inc.; belongs to the Abbott Vascular speakers' bureau, and receives honoraria from Boston Scientific ${ }^{1}$, Cleveland Clinic, Complete Conference Management, Cordis, SCAI, University of Southern California, and VIVA Physicians. Dr. Levy receives research grant support (principal investigator: Stent-Assisted Recanalization in acute Ischemic Stroke, SARIS), other research support (devices), and honoraria from Boston Scientific ${ }^{1}$ and research support from Codman and Shurtleff, Inc. and ev3/Covidien Vascular Therapies; has ownership interests in Intratech Medical Ltd. and Mynx/Access Closure; serves as a consultant on the board of Scientific Advisors to Codman and Shurtleff, Inc.; serves as a consultant per project and/or per hour for Codman and Shurtleff, Inc., ev3/Covidien Vascular Therapies, and TheraSyn Sensors, Inc., and receives fees for carotid stent training from Abbott Vascular and ev3/Covidien Vascular Therapies. Dr. Levy receives no consulting salary arrangements. All consulting is per project and/or per hour. Dr. Ogilvy serves as a consultant to Mizuho America. Dr. Siddiqui has received research grants from the National Institutes of Health (co-investigator: NINDS 1R01NS064592-01A1, Hemodynamic induction of pathologic remodeling leading to intracranial aneurysms) and the University at Buffalo (Research Development Award); holds financial interests in Hotspur, Intratech Medical, StimSox, and Valor Medical; serves as a consultant to Codman and Shurtleff, Inc., Concentric Medical, ev3/Covidien Vascular Therapies, GuidePoint Global Consulting, and Penumbra; belongs to the speakers' bureaus of Codman and Shurtleff, Inc. and Genentech; serves on an advisory board for Codman and Shurtleff, and has received honoraria from Abbott Vascular, American Association of Neurological Surgeons' and Annual Peripheral Angioplasty and All that Jazz courses, an emergency medicine conference, Genentech, Neocure Group LLC, an Emergency Medicine Conference, and from Abbott Vascular and Codman and Shurtleff, Inc. for training other neurointerventionists in carotid stenting and for training physicians in endovascular stenting for aneurysms. Dr. Siddiqui receives no consulting salary arrangements. All consulting is per project and/or per hour.

1 Boston Scientific's neurovascular business has been acquired by Stryker. 


\section{References}

$\checkmark 1$ Benoit BG, Wortzman G: Traumatic cerebral aneurysms. Clinical features and natural history. J Neurol Neurosurg Psychiatry 1973; 36:127-138.

-2 Buckingham MJ, Crone KR, Ball WS, Tomsick TA, Berger TS, Tew JM Jr: Traumatic intracranial aneurysms in childhood: two cases and a review of the literature. Neurosurgery 1988;22:398-408.

$\checkmark 3$ Ventureyra EC, Higgins MJ: Traumatic intracranial aneurysms in childhood and adolescence. Case reports and review of the literature. Childs Nerv Syst 1994;10:361-379.

-4 Dunn IF, Woodworth GF, Siddiqui AH, Smith ER, Vates GE, Day AL, Goumnerova LC: Traumatic pericallosal artery aneurysm: a rare complication of transcallosal surgery. Case report. J Neurosurg 2007;106:153-157.

$\checkmark 5$ Lempert TE, Halbach VV, Higashida RT, Dowd CF, Urwin RW, Balousek PA, Hieshima GB: Endovascular treatment of pseudoaneurysms with electrolytically detachable coils. AJNR Am J Neuroradiol 1998;19:907911.

-6 Sutton LN, Gusnard D, Bruce DA, Fried A, Packer RJ, Zimmerman RA: Fusiform dilatations of the carotid artery following radical surgery of childhood craniopharyngiomas. J Neurosurg 1991;74:695-700.

-7 Tovi F, Leiberman A, Hertzanu Y, Golcman L: Pseudoaneurysm of the internal carotid artery secondary to tonsillectomy. Int J Pediatr Otorhinolaryngol 1987;13:69-75.

8 Awasthi D, Dowd G: Lessons learned from a case of a traumatic intracranial aneurysm. http://www.medschool.lsuhsc.edu/neurosurgery/nervecenter/traumatican.html (accessed April 24, 2012).

>9 Tirakotai W, Sure U, Benes L, Aboul-Enein H, Schulte DM, Riegel T, Bertalanffy H: Successful management of a symptomatic fusiform dilatation of the internal carotid artery following surgery of childhood craniopharyngioma. Childs Nerv Syst 2002;18:717721.
10 Wang X, Chen JX, You C, He M: Surgical management of traumatic intracranial pseudoaneurysms: a report of 12 cases. Neurol India 2008;56:47-51.

11 Sutton LN: Vascular complications of surgery for craniopharyngioma and hypothalamic glioma. Pediatr Neurosurg 1994; 21(suppl 1):124-128.

-12 Fang C, Li MH, Tan HQ, Zhang PL, Zhou B: Endovascular treatment of pseudo-aneurysm occurring after embolization of traumatic carotid cavernous fistula with detachable balloons. Chin Med J (Engl) 2008;121: 1487-1491.

$>13$ Fiorella D, Albuquerque FC, Deshmukh VR, Woo HH, Rasmussen PA, Masaryk TJ, McDougall CG: Endovascular reconstruction with the neuroform stent as monotherapy for the treatment of uncoilable intradural pseudoaneurysms. Neurosurgery 2006;59:291300.

14 Gralla J, Brekenfeld C, Schmidli J, Caversaccio $\mathrm{M}$, Do DD, Schroth G: Internal carotid artery aneurysm with life-threatening hemorrhages in a pediatric patient: endovascular treatment options. J Endovasc Ther 2004;11 734-738.

15 Hopkins JK, Shaibani A, Ali S, Khawar S, Parkinson R, Futterer S, Russell EJ, Getch C: Coil embolization of posttraumatic pseudoaneurysm of the ophthalmic artery causing subarachnoid hemorrhage. Case report. J Neurosurg 2007;107:1043-1046.

- 16 Li MH, Li YD, Gao BL, Fang C, Luo QY, Cheng YS, Xie ZY, Wang YL, Zhao JG, Li Y, Wang W, Zhang BL, Li M: A new covered stent designed for intracranial vasculature: application in the management of pseudoaneurysms of the cranial internal carotid artery. AJNR Am J Neuroradiol 2007;28:1579_ 1585.

17 Medel R, Crowley RW, Hamilton DK, Dumont AS: Endovascular obliteration of an intracranial pseudoaneurysm: the utility of Onyx. J Neurosurg Pediatr 2009;4:445-448.

$\checkmark 18$ Phatouros CC, Sasaki TY, Higashida RT, Malek AM, Meyers PM, Dowd CF, Halbach VV: Stent-supported coil embolization: the treatment of fusiform and wide-neck aneurysms and pseudoaneurysms. Neurosurgery 2000;47:107-115.
19 Pride GL Jr, Replogle RE, Rappard G, Graybeal CL, White J, Purdy P: Stent-coil treatment of a distal internal carotid artery dissecting pseudoaneurysm on a redundant loop by use of a flexible, dedicated nitinol intracranial stent. AJNR Am J Neuroradiol 2004;25:333-337.

20 Sim SY, Shin YS, Yoon SH: Endovascular internal trapping of traumatic pericallosal pseudoaneurysm with hydrogel-coated selfexpandable coil in a child: a case report. Surg Neurol 2008;69:418-422.

-21 Lakhanpal SK, Glasier CM, James CA, Angtuaco EJ: MR and CT diagnosis of carotid pseudoaneurysm in children following surgical resection of craniopharyngioma. Pediatr Radiol 1995;25:249-251.

22 Levy ML, Rezai A, Masri LS, Litofsky SN, Giannotta SL, Apuzzo ML, Weiss MH: The significance of subarachnoid hemorrhage after penetrating craniocerebral injury: correlations with angiography and outcome in a civilian population. Neurosurgery 1993;32: $532-540$

23 Amirjamshidi A, Rahmat H, Abbassioun K: Traumatic aneurysms and arteriovenous fistulas of intracranial vessels associated with penetrating head injuries occurring during war: principles and pitfalls in diagnosis and management. A survey of 31 cases and review of the literature. J Neurosurg 1996;84: 769-780.

-24 Holmes B, Harbaugh RE: Traumatic intracranial aneurysms: a contemporary review. J Trauma 1993;35:855-860.

25 Glasgow JF: Reye's syndrome: the case for a causal link with aspirin. Drug Saf 2006;29: 1111-1121.

26 Veeravagu A, Guzman R, Patil CG, Hou LC, Lee M, Steinberg GK: Moyamoya disease in pediatric patients: outcomes of neurosurgical interventions. Neurosurg Focus 2008; 24:E16 